\title{
Communication
}

\section{Correcting an Error in Some Interpretations of Atmospheric ${ }^{14} \mathrm{C}$ Data}

\author{
David Evans Andrews \\ Department of Physics and Astronomy, University of Montana, Missoula, USA \\ Email address: \\ Dave.Andrews@mso.umt.edu
}

To cite this article:

David Evans Andrews. Correcting an Error in Some Interpretations of Atmospheric ${ }^{14}$ C Data. Earth Sciences. Vol. 9, No. 4, 2020 , pp. $126-129$. doi: 10.11648/j.earth.20200904.12

Received: July 5, 2020; Accepted: August 4, 2020; Published: August 13, 2020

\begin{abstract}
The variable " $\Delta{ }^{14} \mathrm{C}$ ", commonly used in radiocarbon dating and tracing applications to quantify ${ }^{14} \mathrm{C}$ levels, is a measure of the ratio of the radioisotope ${ }^{14} \mathrm{C}$ to other carbon in a sample. After atmospheric nuclear testing in the 1950's and 1960 's nearly doubled atmospheric ${ }^{14} \mathrm{C}$, the later evolution of $\Delta^{14} \mathrm{C}$ allowed insights into the dynamics of carbon exchange between the atmosphere and terrestrial and marine sinks. But a few authors without backgrounds in isotope measurements have confused $\Delta{ }^{14} \mathrm{C}$ with excess ${ }^{14} \mathrm{C}$ concentration. They erroneously interpret the present recovery of $\Delta{ }^{14} \mathrm{C}$ to near its pre bomb test value as evidence that atmospheric ${ }^{14} \mathrm{C}$ concentration has returned to its earlier value. From this they reach further incorrect conclusions about the fate of anthropogenic $\mathrm{CO}_{2}$ introduced into the atmosphere by fossil fuel burning. An estimate of the true time dependence of atmospheric ${ }^{14} \mathrm{C}$ concentration over the past century, calculated from averaged atmospheric $\Delta^{14} \mathrm{C}_{\text {and }} \mathrm{CO}_{2}$ data is presented. The data show that ${ }^{14} \mathrm{C}$ concentrations remain over $30 \%$ above 1950 values, and have begun to increase, even as $\Delta^{14} \mathrm{C}$ continues to fall. This confirms the prediction of a conventional model of the carbon cycle. The unconventional models of carbon dynamics motivated by the mistake, on the other hand, are excluded by the properly interpreted ${ }^{14} \mathrm{C}$ data.
\end{abstract}

Keywords: Carbon Accumulation, Radiocarbon, Atmospheric $\mathrm{CO}_{2}$

\section{Introduction}

A broad consensus of both climate scientists and the public accepts that human activities such as burning fossil fuels are responsible for the worrisome increase in atmospheric $\mathrm{CO}_{2}$ over the last century. Nonetheless a few continue to argue that the increase is "natural" and outside of human control [1-4]. While extensive rebuttals of these arguments have been made elsewhere [5, 6], the common motivating factor for the maverick papers appears not to have been identified before now: all make the same mistake in interpreting ${ }^{14} \mathrm{C}$ data collected and presented by others. In this note we will show that a correct understanding of ${ }^{14} \mathrm{C}$ data excludes models motivated by the error.

\section{The Error Explained}

\subsection{An Imbalance in Atmospheric ${ }^{14}$ C Creates an Opportunity}

The success of radiocarbon dating is predicated on an at least approximately stable abundance ratio between ${ }^{14} \mathrm{C}$ and the other carbon isotopes in the natural environment for tens of thousands of years. (See for example [7]) Natural ${ }^{14} \mathrm{C}$ is produced in the upper atmosphere from cosmic ray generated neutrons interacting with nitrogen. ${ }^{14} \mathrm{CO}_{2}$ is ultimately formed and distributed throughout the biosphere. A balance between the production of ${ }^{14} \mathrm{C}$ and its radioactive decay (half-life of $\sim 5730$ years) maintained ${ }^{14} \mathrm{C}$ at approximately 1 part per trillion of the total atmospheric carbon through about 1950. But the balance was upset when atmospheric nuclear weapon testing nearly doubled the atmospheric ${ }^{14} \mathrm{C}$ content, during the decade beginning about 1955. While this will complicate future radiocarbon dating applications, several groups saw an opportunity to use the imbalance to study and refine models of the dynamics of carbon transport [7-9]. As a result, the evolution of atmospheric ${ }^{14} \mathrm{C}$ since 1965 is well documented [10-12]. The data are generally presented as a plot of " $\Delta{ }^{14} C$ " versus time, for example as shown in Figure 1. 


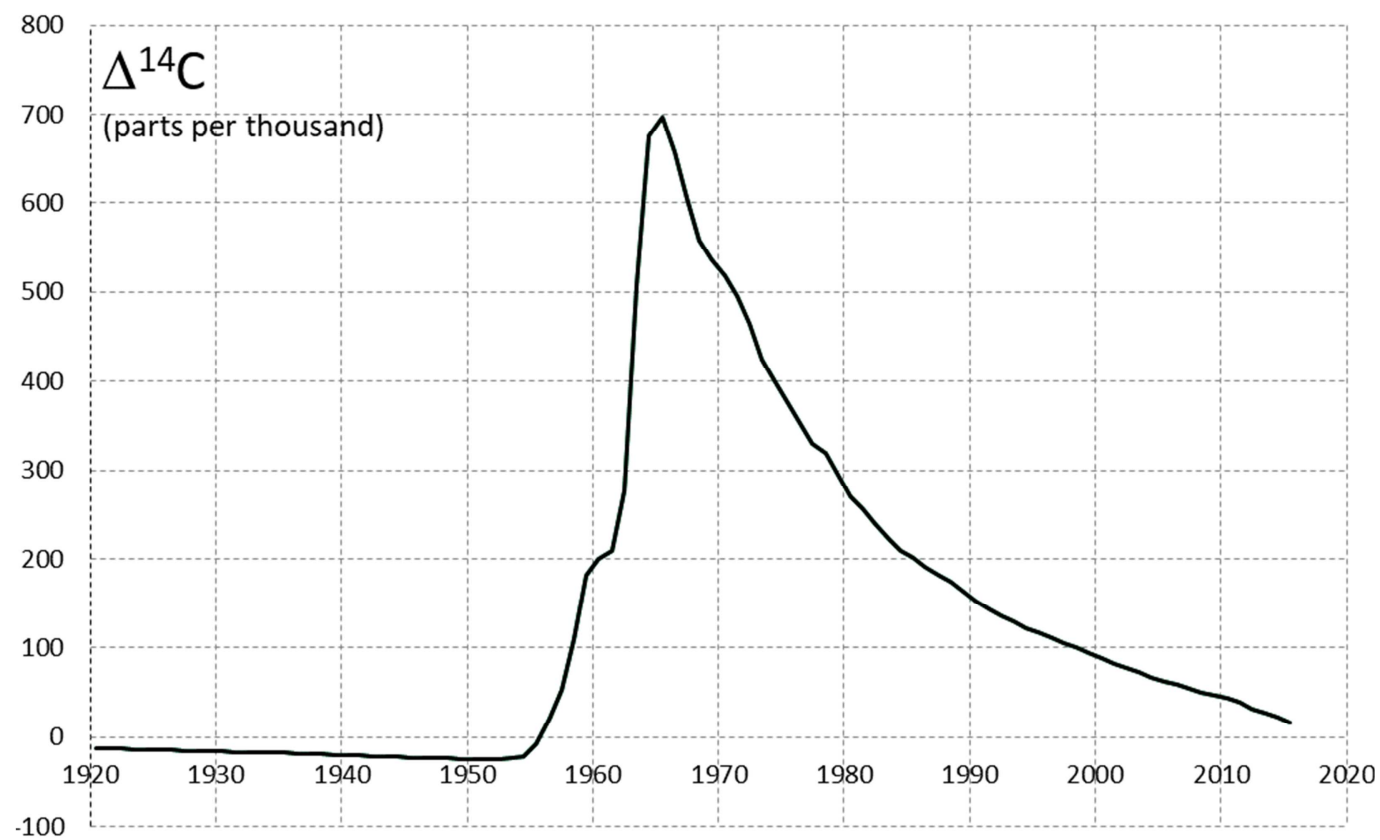

Figure 1. Atmospheric nuclear testing in the 1950's and '60's increased atmospheric ${ }^{14} \mathrm{C}$ by about $70 \%$ (700ppt). The recovery following cessation of testing is well described by an exponential decay towards 0 with a time constant of about 16 years. The above plot is an attempt at a global average for this variable, with northern hemisphere, southern hemisphere, and tropical data for each year from [12] weighted equally.

\subsection{Understanding $\Delta^{14} C$}

${ }^{14} \mathrm{C}$ dating measurements use isotope abundance ratios rather than absolute concentrations. Not only are ratios easier to measure accurately, the ${ }^{14} \mathrm{C}$ content of a sample by itself is impossible to interpret, unless the concentration of other carbon isotopes is also known. When a sample of biological origin was alive, exchanging carbon with the atmosphere, isotope ratios in the organism presumably matched those in the atmosphere at that time (ignoring small differences from fractionation). After the organism died and became isolated from the atmosphere, the slow radioactive decay of ${ }^{14} \mathrm{C}$ changed the isotope ratio, since the ${ }^{12} \mathrm{C}$ content was stable.

Measuring the current isotope ratio, and knowing the half-life of ${ }^{14} \mathrm{C}$, then enables an estimate of the sample's age. Similarly, in tracing flows of carbon, gradients in the more accurately known isotope ratios are the standard tool.

Given these considerations, a useful variable would measure the fractional deviation from a standard of a measured quantity proportional to an isotope abundance ratio. By convention this is expressed in parts per thousand. Thus $\Delta{ }^{14} \mathrm{C}$ is defined as:

$$
\Delta^{14} C=1000\left[\frac{A_{\text {measured }}}{A_{\text {standard }}}-1\right]
$$

A convenient operational choice for the standard depends upon the technology used for the measurement $[8,13,14]$. The quantity " $A_{\text {measured" }}$ can be the specific activity of a sample, i.e. Becquerels per kg of carbon (which depends on ${ }^{14} \mathrm{C} / \mathrm{C}_{\text {total }}$ ) [13], or Becquerels per liter of Oxalic acid [14] (which, since the fraction of carbon in Oxalic acid is fixed, also reduces to a measure of $\left.{ }^{14} \mathrm{C} / \mathrm{C}_{\text {total }}\right)$. $\mathrm{A}_{\text {measured }}$ can also be a direct measurement of ${ }^{14} \mathrm{C} /{ }^{13} \mathrm{C}$ (or ${ }^{14} \mathrm{C} /{ }^{12} \mathrm{C}$ ) by an accelerator mass spectrometer [8]. The quantity " $\mathrm{A}_{\text {standard" }}$ " must of course be in the same units as $\mathrm{A}_{\text {measured }}$ and is established by convention. Examples are $\mathrm{A}_{\text {standard }}=226 \mathrm{~Bq} / \mathrm{kgC}$ [14] and $\mathrm{A}_{\text {standard }}=$ $1.176 \times 10^{-12} \mathrm{~mol}^{14} \mathrm{C} / \mathrm{molC}$ [8]. These choices make atmospheric $\Delta{ }^{14} \mathrm{C}$ near zero, but slightly negative, just prior to the bomb tests, as shown in Figure 1. Corrections for the fractionation of isotopes during sample preparation or in biological processes are important considerations in making different measurement technologies give consistent results. But as these corrections are much smaller than the error about to be described, there is no need to elaborate further in this simplified overview.

\subsection{Misusing $\Delta^{14} \mathrm{C}$}

${ }^{14} \mathrm{C}$ specialists are interested in isotope ratios, and $\Delta{ }^{14} \mathrm{C}$ serves them well. Its use is so ingrained that its definition is usually omitted from papers presenting ${ }^{14} \mathrm{C}$ data. It is sometimes used as a proxy for comparing concentrations of ${ }^{14} \mathrm{C}$ but that is dangerous, and this is where the problem arises. In a dating measurement the ${ }^{14} \mathrm{C}$ changes, making $\Delta{ }^{14} \mathrm{C}$ change, while the ${ }^{12} \mathrm{C}$ is fixed. But if this variable is used in atmospheric studies of ${ }^{14} \mathrm{C}$ changes with a baseline of $\sim 60$ years, not only the ${ }^{14} \mathrm{C}$ is changing. The time dependence of $\Delta^{14} \mathrm{C}$ now reflects changes in the concentration of all the carbon as well as ${ }^{14} \mathrm{C}$ concentration changes. For example, as $\Delta^{14} \mathrm{C}$ approaches 0 in 2020 as seen in Figure 1, this does not mean that ${ }^{14} \mathrm{C}$ concentrations have nearly returned to 1955 values. It means that the isotope abundance ratio has nearly returned to its previous value. Therefore, since atmospheric ${ }^{12} \mathrm{CO}_{2}$ has increased by about $30 \%$ since 1955 , the ${ }^{14} \mathrm{C}$ concentration remains well above its pre-bomb test value. 


\section{Finding the True ${ }^{14} \mathrm{C}$ Concentration}

It is of course possible to determine the true ${ }^{14} \mathrm{C}$ concentration as a function of time (call it ${ }^{14} \mathrm{C}(\mathrm{t})$ ), from $\Delta^{14} \mathrm{C}$ if we also know how the concentration of the rest of the carbon varies with time. (Call that function $\mathrm{C}(\mathrm{t})$ ). Rearranging equation 1 , making $\mathrm{A}={ }^{14} \mathrm{C} / \mathrm{C}$, and explicitly identifying the time dependent factors gives

$$
{ }^{14} C(t)=C(t) \times \frac{{ }^{14} c_{s t d}}{C_{s t d}} \times\left[1+.001 \times \Delta \Delta^{14} C(t)\right]
$$

To estimate $\mathrm{C}(\mathrm{t})$, we use the Mauna Loa trend data (which filters out the seasonal variation) for 1958 and after, and ice core data for the years before [15]. This familiar curve is shown in Figure 2. Also shown in Figure 2 is our estimate of the global average ${ }^{14} \mathrm{C}$ concentration over the last century, computed from this $\mathrm{C}(\mathrm{t})$, the Figure 1 data for $\Delta^{14} \mathrm{C}$. and ${ }^{14} \mathrm{C}_{\text {std }} / \mathrm{C}_{\text {std }}=1.176 \times 10^{-12} \mathrm{~mol}{ }^{14} \mathrm{C} / \mathrm{molC}$. While plots of $\Delta{ }^{14} \mathrm{C}$ through the bomb test period appear frequently in the literature, plots of ${ }^{14} \mathrm{C}$ concentration are surprisingly scarce and qualitatively different. The concentration curve shown should be taken as global average data derived from the isotope ratio measurements with minimal model assumptions.

\section{Discussion}

Essenhigh [1], Harde [2, 3], and Berry [4] took the isotope ratio curve shown in Figure 1 to be the ${ }^{14} \mathrm{C}$ concentration curve, which is correctly shown in Figure 2. Essenhigh labels an axis ${ }^{\text {" } 14} \mathrm{C}$ concentration" for a plot that is clearly of $\Delta^{14} \mathrm{C}$. Harde and Berry label their axes correctly but misinterpret the meaning and have asserted wrongly that $\Delta^{14} \mathrm{C}$ is equivalent to concentration (personal communications). Looking at plots similar to Figure 1, the three authors erroneously concluded that after atmospheric nuclear testing ceased, the "pulse" of extra $14 \mathrm{C}$ introduced by the tests exponentially disappeared from the atmosphere with a time constant of approximately 16 years. They reasoned that anthropogenic carbon from fossil fuel burning would behave similarly, and ultimately concluded that human activity was not a major contributor to increasing atmospheric $\mathrm{CO}_{2}$. Indeed, the isotope ratio curve shown in Figure 1, interpreted as a concentration curve, invites a single time constant model for absorption of atmospheric ${ }^{14} \mathrm{C}$ by terrestrial or oceanic sinks. Were this the true concentration curve, it would be powerful evidence for their "alternative carbon cycle" models. But it is not. Being built on this mistake, the "alternative models" are incompatible with the true ${ }^{14} \mathrm{C}$ concentration data.

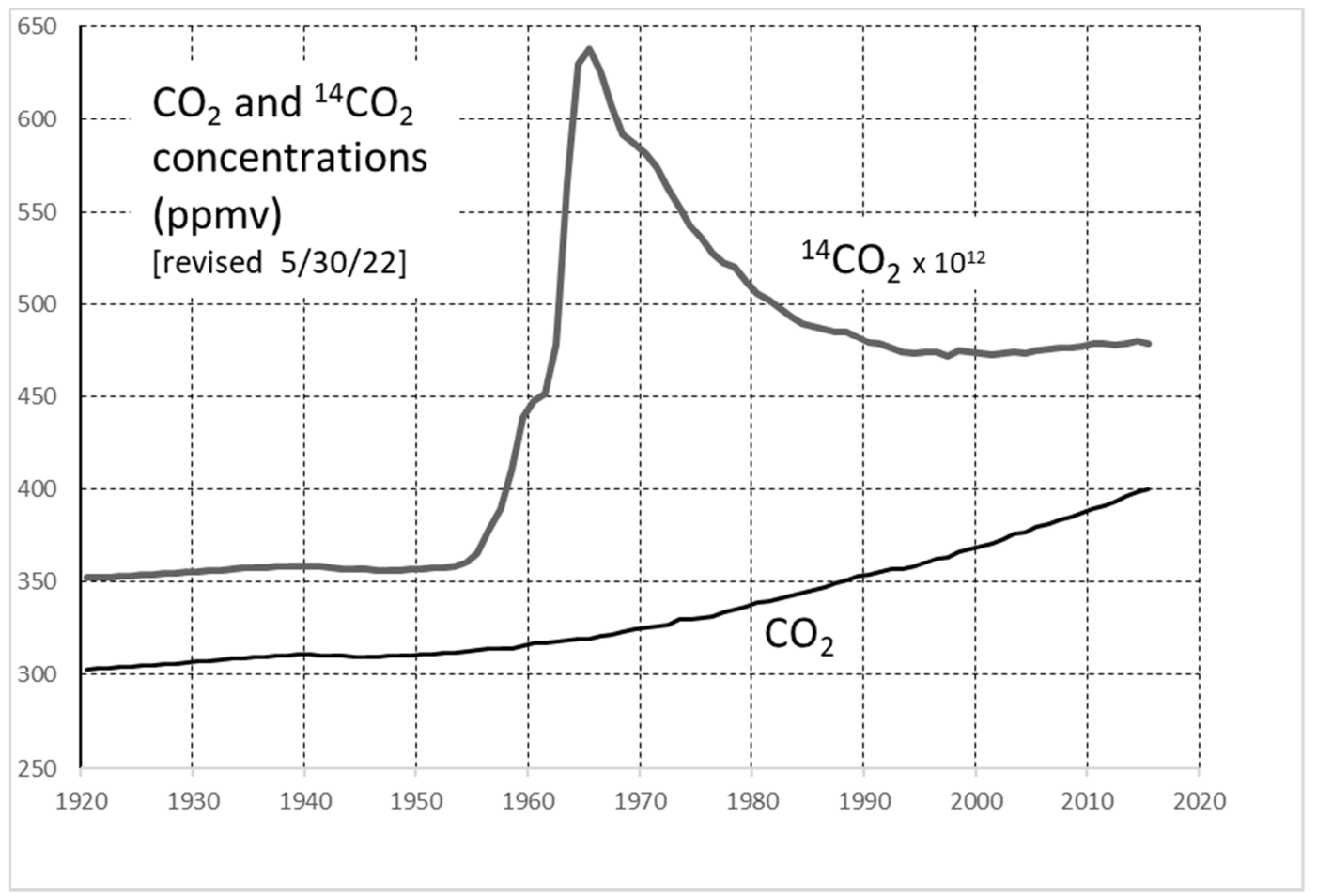

Figure 2. The atmospheric concentration of $\mathrm{CO}_{2}$ and ${ }^{14} \mathrm{CO}_{2}$ in the last century. The $\mathrm{CO}_{2}$ follows the well-known "Keeling curve". The ${ }^{14} \mathrm{CO}_{2}$ concentration is multiplied by a factor of 1 trillion. ${ }^{14} \mathrm{C}$ concentration in 2020 remains about $30 \%$ higher than before the atmospheric nuclear testing. But the isotope ratio in 2020 is not far from its 1920 value, as can be ascertained from either this figure or Figure 1.

The bomb tests left an atmospheric $\Delta^{14} \mathrm{C}$ excess compared to $\Delta^{14} \mathrm{C}$ in terrestrial and oceanic sinks. The rapid initial decrease in ${ }^{14} \mathrm{C}$ concentration after the tests ended is a result of exchange of atmospheric ${ }^{14} \mathrm{C}$ with ${ }^{12} \mathrm{C}$ in those sinks. But the full evolution of the ${ }^{14} \mathrm{C}$ concentration curve in Figure 2 shows that this exchange does not remove ${ }^{14} \mathrm{C}$ from the atmosphere permanently. Models show that roughly $40 \%$ of the increase of atmospheric ${ }^{14} \mathrm{C}$ since 1950 is attributable to the bomb tests [7]. It has not been absorbed harmlessly by the land and sea. One could conclude that fossil fuel $\mathrm{CO}_{2}$ produced during the last century is similarly still with us.

The data show that ${ }^{14} \mathrm{C}$ concentration in the atmosphere is now actually increasing. This at first sight seems to contradict the "Suess effect" [16]. Since fossil fuel emissions are largely 
${ }^{14} \mathrm{C}$ free, the carbon having been in the ground much longer than the ${ }^{14} \mathrm{C}$ lifetime, one expects the ${ }^{14} \mathrm{C} /{ }^{12} \mathrm{C}$ ratio to fall as ${ }^{14} \mathrm{C}$ in the carbon cycle is diluted, and this is evident in Figure 1 data prior to 1950 . However the observed increase in the concentration, not the ratio, around the year 2000 was predicted [7]. Caldeira et al. found that new ${ }^{12} \mathrm{C}$ from fossil fuels displaces ${ }^{14} \mathrm{C}$ in terrestrial and oceanic sinks and competes with the continued influx of cosmic ray generated ${ }^{14} \mathrm{C}$ for places in those sinks. In other words, higher atmospheric carbon concentrations are now required to move carbon to the terrestrial and oceanic sinks. The analysis predicts that $\Delta^{14} \mathrm{C}$ ultimately will again go negative from the Suess effect, even as the ${ }^{14} \mathrm{C}$ concentration continues to rise. Note that the idea that ${ }^{14} \mathrm{C}$ is now being "pushed" from the oceans to make room for new anthropogenic ${ }^{12} \mathrm{C}$ is quite different from the idea that the overall increase in atmospheric $\mathrm{CO}_{2}$ is due to ocean outgassing due to temperature increases from an unspecified cause [2, 3]. In the latter hypothesis, a decrease in ocean carbon would be expected, which is not seen.

\section{Conclusions}

Conventional carbon cycle models have been successful in predicting the evolution of atmospheric ${ }^{14} \mathrm{C}$ concentration following its sharp increase after atmospheric nuclear tests. Unconventional models motivated by a misinterpretation of the isotope ratio variable " $\Delta{ }^{14} \mathrm{C}$ " are excluded when the error is corrected.

\section{Acknowledgements}

Jocelyn Turnbull kindly provided a spreadsheet of the Wellington data, and insights into ${ }^{14} \mathrm{C}$ protocols. Peter Koehler steered me towards global data sets. Gavin Cawley and Jerry W. Elwood made several suggestions to improve the clarity of the presentation.

Three of the errant papers cited here [2-4] have been published by the same publishing group. This paper has been submitted to that same group to correct errors that those authors have declined to acknowledge.

The author received no financial support for this work and has no conflicts of interest.

All data used in this paper is publicly available in the references cited.

\section{References}

[1] Essenhigh, R. H. (2009). Potential dependence of global warming on the residence time (RT) in the atmosphere of anthropogenically sourced carbon dioxide. Energy \& Fuels, 23, 2773-2784.

[2] Harde, H.(2017). Scrutinizing the carbon cycle and $\mathrm{CO}_{2}$ residence time in the atmosphere. Global and Planetary Change, 152, 19-26.
[3] Harde, H. (2019). What humans contribute to atmospheric $\mathrm{CO}_{2}$ : Comparison of carbon cycle models with observations. Earth Sciences. 8 (3), 139-159. doi: 10.11648/j.earth.20190803.13.

[4] Berry, E. X. (2019). Human $\mathrm{CO}_{2}$ emissions have little effect on atmospheric $\mathrm{CO}_{2}$. International Journal of Atmospheric and Oceanic Sciences, 3 (1), 13-26. doi: 10.11648/j.ijaos.20190301.13.

[5] Cawley, G. C. (2011). On the atmospheric residence time of anthropogenically sourced $\mathrm{CO}_{2}$. Energy Fuels 25, 5503-5513, http://dx.doi.org/10.1021/ef200914u.

[6] Koehler, P., Hauck, J., Volker, C,. Wolf-Gladrow, D. A., Butzin, M, Halpern, J. B. et al.(2017) Comment on "Scrutinizing the carbon cycle and $\mathrm{CO}_{2}$ residence time in the atmosphere by $\mathrm{H}$. Harde". Global and Planetary Change. 164, 67-71.

[7] Caldeira, K., Raul, G. H., and Duffy, P. B. (1998). Predicted net efflux of radiocarbon from the ocean and increase in atmospheric radiocarbon content. Geophysical Research Letters, 25 (20), 3811-3814.

[8] Turnbull, J., Rayne, P., Miller, J., Naegler, T., Ciais, P., Cozic, A (2009). On the use of ${ }^{14} \mathrm{CO}_{2}$ as a tracer for fossil fuel $\mathrm{CO}_{2}$ : Quantifying uncertainties using an atmospheric transport model., Journal of Geophysical Research, 114, D22302. https://doi.org/10.1029/2009JD012308

[9] Levin, I. and Hesshaimer, V. (2000). Radiocarbon: A unique tracer of global carbon cycle dynamics., Radiocarbon, 42 (1), 69-80.

[10] Turnbull, J. C., Mikaloff Fletcher, S. E., Ansell, I., Brailsford, G. W, Moss, R. C., Norris, M. W, et al. (2017). Sixty years of radiocarbon dioxide measurements at Wellington, New Zealand: 1954-2014. Atmos. Chem. Phys., 17, 14771-14784. https://doi.org/10.5194/acp-17-14771-2017.

[11] Hua, Q., Barbetti, M., Rakowski, A. Z. (2013). Atmospheric radiocarbon for the period 1950-2010. Radiocarbon, 55, pp. 2059-2072. https://doi.org/10.2458/azu_js_rc.v55i2.16177

[12] Graven, H., Allison, C. E., Etheridge, D. M., Hammer, S., Keeling, R. F., Levin, I., et al. (2017). Compiled records of carbon isotopes in atmospheric $\mathrm{CO}_{2}$ for historical simulations in CMIP6, Geosci. Model Dev., 10, 4405-4417, https://doi.org/10.5194/gmd-10-4405-2017.

[13] Stenstrom, K. E., Skog, G., Gerogiadou, Genberg. J., Johansson, A. (2011). A guide to radiocarbon units and calculations. Lund University, LUNFD6 (NFFR-3111) /1-17/ (2011).

https://www.hic.ch.ntu.edu.tw/AMS/A\%20guide\%20to\%20ra diocarbon\%20units\%20and\%20calculations.pdf

[14] Stuiver, M. and Polach, H.(1977). Discussion: Reporting of ${ }^{14} \mathrm{C}$ data". $\quad$ Radiocarbon, $19 \quad$ (3), 355-363. https://journals.uair.arizona.edu/index.php/radiocarbon/article/ viewFile/493/498

[15] World Data Centre for Greenhouse Gasses http://gaw.kishou.go.jp/

[16] Suess, H. E. (1955), Radiocarbon concentration in modern wood", Science, 122, 415-417. 